\title{
Upper airway radiographs in infants with upper airway insufficiency
}

\author{
S L Tonkin, S L Davis, T R Gunn
}

\begin{abstract}
Upper airway measurements in nine infants considered to be at risk of upper airway insufficiency, six of whom presented after an apnoeic episode, were compared with measurements taken in two age groups of healthy infants. Paired, inspiratory and expiratory, lateral upper airway radiographs were obtained while the infants were awake and breathing quietly. The radiographs of all nine infants demonstrated narrowing in the oropharyngeal portion of the airway during inspiration and in six infants there was ballooning of the upper airway during expiration. Seven of the nine infants subsequently experienced recurrent apnoeic episodes which required vigorous stimulation to restore breathing. Experience suggests that respiratory phase timed radiographs are a useful adjunct to the evaluation of infants who are suspected of having upper airway dysfunction. They provide information regarding both the dimensions and compliance of the upper airway as well as the site of any restriction.
\end{abstract}

(Arch Dis Child 1994; 70: 523-529)

Infants with upper airway dysfunction may be at increased risk for sudden infant death syndrome (SIDS). ${ }^{12}$ To date there has been no reliable way in the neonatal period to identify infants who may subsequently experience significant upper airway obstruction. Clinical signs of inspiratory intercostal and lateral pharyngeal indrawing in infants who are free of pulmonary disease indicate that increased upper airway resistance is likely in such infants. In the obstructive sleep apnoea syndrome of adults and children, airway obstruction results from collapse of the oropharynx during inspiration as shown in studies using flexible fibro-optic endoscopy ${ }^{3}$ and pharyngeal pressure recordings. ${ }^{4}$ Partial upper airway obstruction may also be demonstrated by these techniques. Both endoscopy and pressure recordings are invasive procedures and are not available in all paediatric services for the clinical evaluation of infants.

In a previous report we have shown that measurement of the upper airway in lateral neck radiographs taken during specific phases of the respiratory cycle is feasible when the $x$ ray machine is triggered by a monitor that detects respiratory movement. In a group of healthy infants the dimensions of the upper airway were documented during inspiration and during expiration, in the newborn period and at 6 weeks of age using this method. ${ }^{5}$ We now report similarly obtained upper airway measurements in nine infants at risk of upper airway insufficiency, seven of whom subsequently demonstrated significant apnoea.

\section{Subjects and methods}

There were nine infants in this study, six were referred after apparent life threatening events (ALTEs). One infant with Pierre Robin syndrome was identified in the neonatal period because he had a very small jaw and the other neonate because of noisy breathing. One older infant was referred for noisy breathing. None of these infants had lower respiratory tract disease. These nine infants who presented with symptoms suggestive of upper airway dysfunction has inspiratory and expiratory lateral upper airway radiographs as in our previous study. ${ }^{5}$ These were obtained with each infant lying on the side with the head in the lateral position and the line from the infraorbital margin to the external auditory canal at a right angle to the spine. All infants were in a quiet awake or drowsy state after being fed and were unsedated. It is important to note that measurements of radiographs taken during crying fail to demonstrate a difference in airway size between the two respiratory phases. The upper airway from below the larynx to the base of the skull including the nasion was imaged. The film was placed in the bucky with anode to film distance $100 \mathrm{~cm}$. The exposures were timed by the use of a modified Graseby (Graseby Medical Ltd) MR10 apnoea monitor. The capsule of the monitor was taped to the infant's abdomen at the level of the umbilicus. The current pulse to the breath indicator light of the Graseby monitor was used to trigger the $x$ ray machine such that exposure was made at the end of the first $20 \%$ of inspiratory movement time for the inspiratory film, and midway between successive inspiratory movements for the expiratory film. The amount of $x$ radiation exposure per pair of films was equivalent to two chest radiographs. All radiographs were obtained under these standard conditions and measurements were made with no correction for cephalometric readings. Cephalometric measurements made from the films included three distances (nasion to sella, nasion to upper jaw, nasion to lower jaw) and three angles (sella-nasion-upper jaw, sella-nasion-lower jaw, upper jaw-nasionlower jaw) as illustrated in fig 1 , the radiograph of the infant with Pierre Robin syndrome (case 2). Upper airway measurements included the distance between anterior and posterior airway walls along the lines, gnathion to anterior sella
Correspondence to: Dr S L Tonkin, Cot Death Association, 5 Clonber
Road, PO Box 28177 , Auckland, New Zealand. Accepted 12 January 1994 


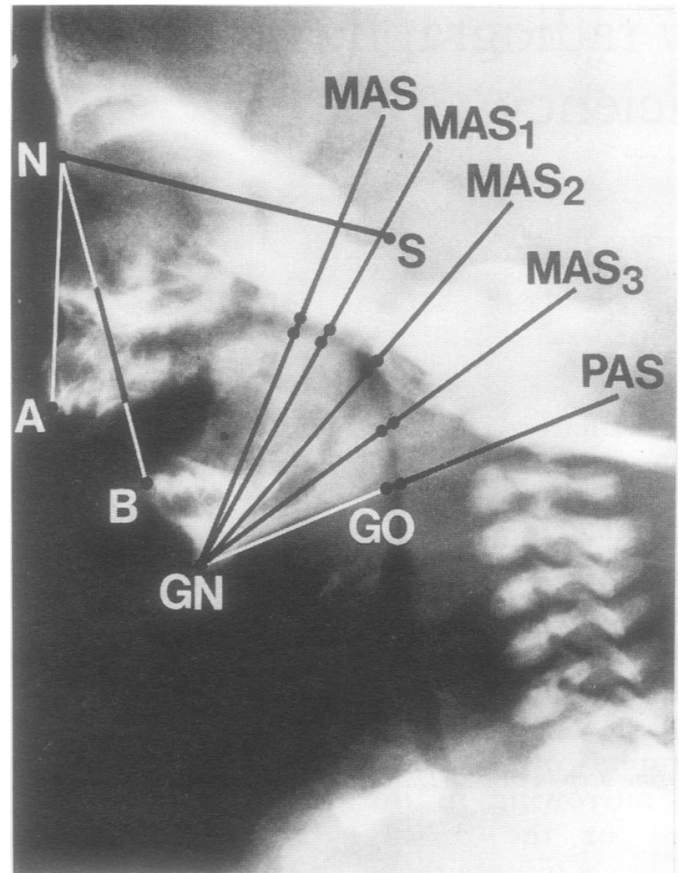

Figure 1 Radiograph of the upper airway during inspiration in quiet nasal breathing in case 2, an infant with Pierre Robin deformity. The tongue protrudes into the palatal cleft during both inspiration and expiration, and the pharyngeal air column is narrowed throughout both phases of respiration. The line drawings indicate the angles formed by the upper jaw-nasion-lower jaw (angle $A-N-B$ ), the sella-nasion-upper jaw (angle $S-N-A$ ), the points where the mid airway space (MAS, MAS $\left., M A S_{2}, M A S_{3}\right)$ measurements are taken, and the points where the posterior airway space (PAS) measurements are taken along the line passing through the gnathion (GN) and gonion (GO).

wall (middle airway space, MAS), gnathion to posterior sella wall $\left(\mathrm{MAS}_{1}\right)$, gnathion to gonion (posterior airway space, PAS), gnathion to a point on anterior airway wall $5 \mathrm{~mm}$ above the gnathion to gonion line on a perpendicular $\left(\mathrm{MAS}_{3}\right)$, and along the line from the gnathion that bisects the angle made by the lines gnathion to MAS 1 and gnathion to $M_{1}$ $\left(\mathrm{MAS}_{2}\right)$, as illustrated in fig 1 .

\section{Results}

The case histories of the patients in this study in order of age are summarised below, none of these infants had lower respiratory tract disease.

CASE 1

This baby girl was born weighing $3280 \mathrm{~g}$ at 38 weeks' gestation, to a gravida 5 para 4 European mother. As a neonate she had abnormally noisy breathing and a retracted jaw (fig 2). Inspiratory intercostal and lateral pharyngeal indrawing were noted. There was no tachypnoea and the chest radiograph was normal. She was discharged from the hospital with an apnoea monitor. When she was 6 weeks old there was a monitor alarm during sleep. The baby was apnoeic and required resuscitation by the mother. An overnight recording of nasal airflow using a thermister, chest impedance, electrocardiogram, and oxygen saturation using a pulse oximeter, in the infant's home demonstrated multiple brief episodes of upper airway obstruction. These

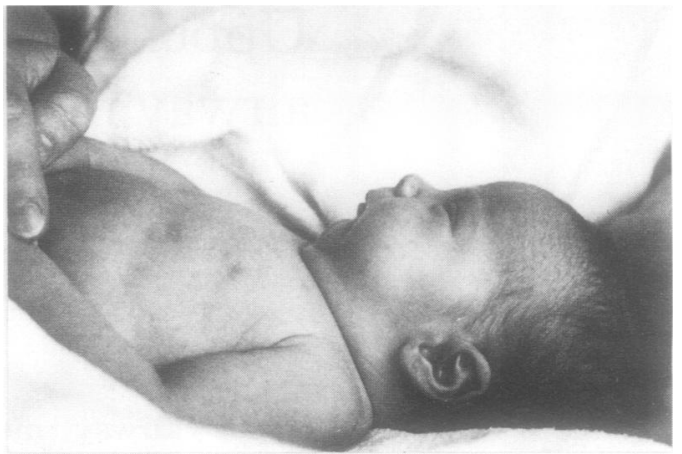

Figure 2 Photograph of case 1, an infant with partial choanal obstruction, showing the retracted jaw and inspiratory intercostal indrawing.

were without significant oxygen desaturation (fig 3). A further four apnoeic episodes requiring resuscitation occurred up to 5 months of age. The family history was of note in that two of four siblings and a first cousin had experienced ALTEs and another first cousin dies from SIDS at 17 weeks (fig 4). The infants with ALTEs and the cousin who died had a similar facial appearance to the patient and all had had noisy breathing.

\section{CASE 2}

This baby boy was born weighing $3460 \mathrm{~g}$ at 40 weeks' gestation to a gravida 2 para 1 European mother. The baby had Pierre Robin syndrome with micrognathia and a cleft palate. In the neonatal period he was nursed on a cardiorespiratory monitor in the prone position. There were no episodes of tachypnoea or apnoea. One episode of duskiness occurred on the second day of life when he regurgitated after a feed. He was discharged from the hospital with an apnoea monitor. When he was 2 weeks of age the alarm alerted the parents to a major apnoeic episode during sleep. They administered mouth to nose resuscitation. On admission to the intensive care unit tracheostomy was required.

\section{CASE 3}

This part Maori baby girl was born weighing $3100 \mathrm{~g}$ at term. When 2 weeks of age she was found by her mother lying still and cyanosed. Breathing was restored after resuscitation. This baby had a thick nasal discharge and physical signs of increased airway resistance: intercostal recession and pharyngeal indrawing with inspiration. She had a repeat apnoea signalled by the home monitor needing mouth to nose resuscitation at 8 weeks.

\section{CASE 4}

This baby boy, the second of twins, was born to a gravida 6 para 3 abortion 2 Maori mother by caesarean section at 36 weeks' gestation weighing $1520 \mathrm{~g}$. At three weeks (corrected for gestational age) his mother noted the onset of noisy breathing, and he had poor weight gain. At 6 weeks he was admitted to hospital after a major ALTE. He had a retracted jaw and marked signs of inspiratory airway restriction. 


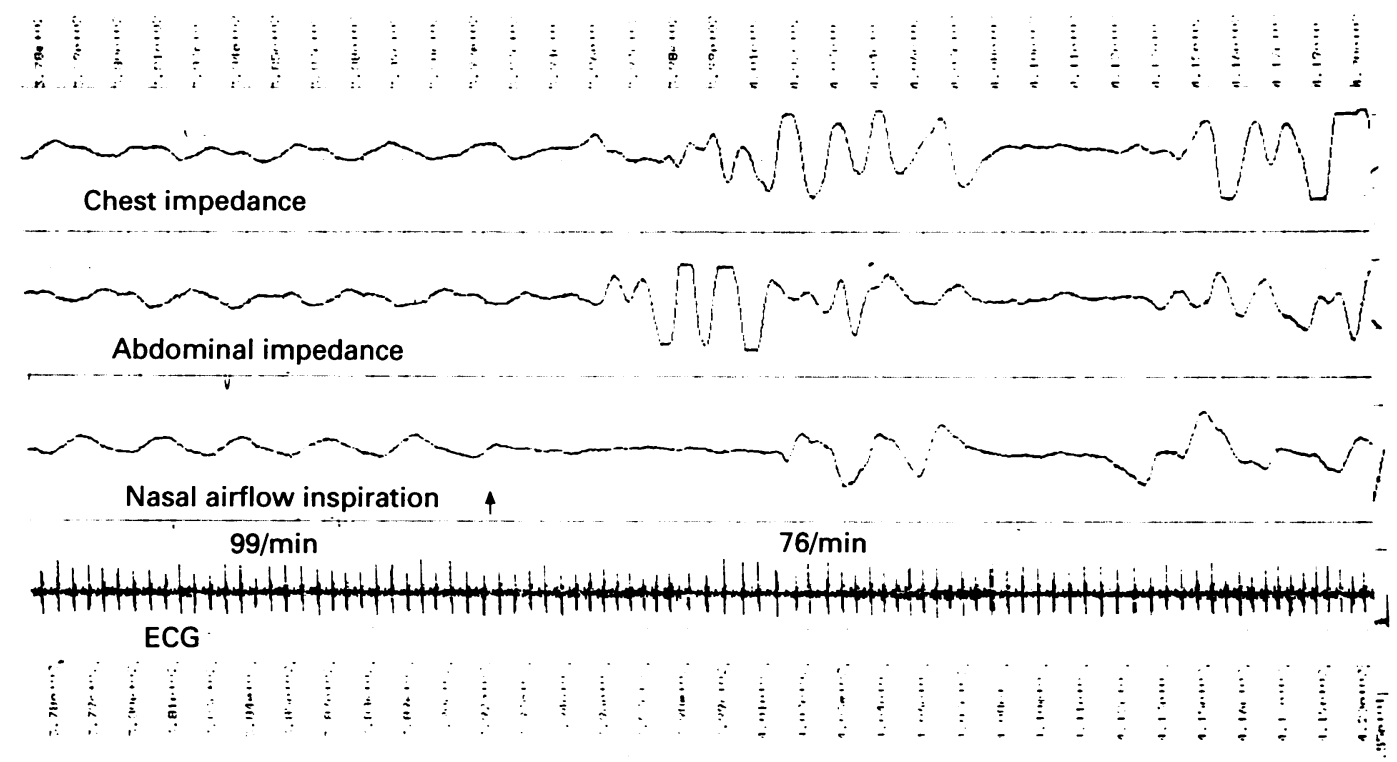

Figure 3 Polygraphic tracing during sleep in case 1. The tracing shows an apnoeic episode that is obstructive at onset as demonstrated by the absence of nasal airflow in the presence of respiratory movements. The episode was terminated with movement and arousal. The instantaneous heart rate decreased from 99 to 76/min during the episode. There was no associated oxygen desaturation.

On inspiration his tongue pivoted back to cleave to the roof of his mouth. Inspiratory stridor was present during both waking and sleep. He was managed with an apnoea monitor and experienced two further apnoeic episodes which required resuscitation. At 6 months he was able to mouth breathe and his weight had caught up to that of his healthy twin.

CASE 5

This baby girl was born weighing $3100 \mathrm{~g}$ at 39 weeks. At 3 weeks old she was found apnoeic and was admitted to hospital. She had noisy breathing and snored and had a large protruding tongue. Her home monitor alarmed four times and each time she needed stimulation to resume breathing.

\section{CASE 6}

This baby boy was born weighing $3610 \mathrm{~g}$ at term. At 5 weeks while being held over his mother's shoulder after feeding he was noticed to have become blue and his mother realised that he was not breathing. He was stimulated and breathing was resumed. This baby had a very small jaw and showed mild intercostal recession with inspiration. His mother was shown how to nurse him without pressing on

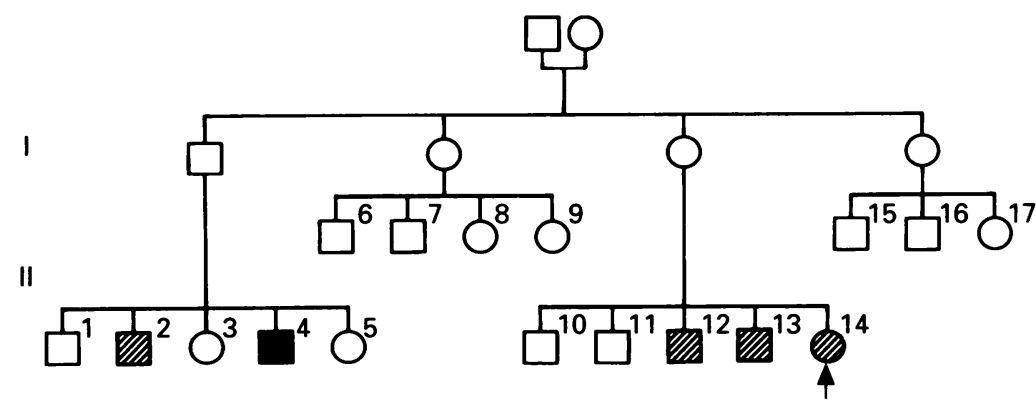

Figure 4 Family tree of case 1 (II 14). Patients with ALTEs: II 2, II 12, II 13, II 14. SIDS victim, II 4. his jaw. He had no further episodes of apnoea while being monitored at home.

CASE 7

This baby girl was born weighing $4200 \mathrm{~g}$ at 41 weeks' gestation. She had been 'snuffly' since birth. She was referred because she had stopped breathing and seemed to 'choke' on several occasions. She had very small external nares, with very prominent alar flaps. Inspiratory pharyngeal and intercostal indrawing was noted. There were two apnoea alarms after discharge which were terminated by stimulation.

CASE 8

This baby girl was born weighing $3380 \mathrm{~g}$ at term. She was referred at 6 weeks of age for noisy breathing and her nurse had noted lateral pharyngeal and intercostal indrawing with inspiration. Her mother said that on one occasion she had been found blue and apnoeic. Apnoea alarms were frequent and stimulation was needed on 15 occasions, the last when the infant was 7 months of age.

CASE 9

This baby boy was born weighing $3800 \mathrm{~g}$ at 40 weeks' gestation. He was referred at 3 months of age because his well baby nurse noticed that he made excessive inspiratory breathing noises and had inspiratory indrawing of his neck tissues.

Cephalometric measurements and upper airway measurements of the five study infants aged 1 to 3 weeks and the measurements of 35 healthy neonates ${ }^{5}$ are given in table 1 and fig 5 . The same measurements of the four study infants 5 weeks to 5 months of age and of 21 healthy infants at 6 weeks old are given in table 2 and fig 6 . In all the study patients the lower mid-airway space, $\mathrm{MAS}_{3}$, was narrower on inspiration than that of the healthy infants 

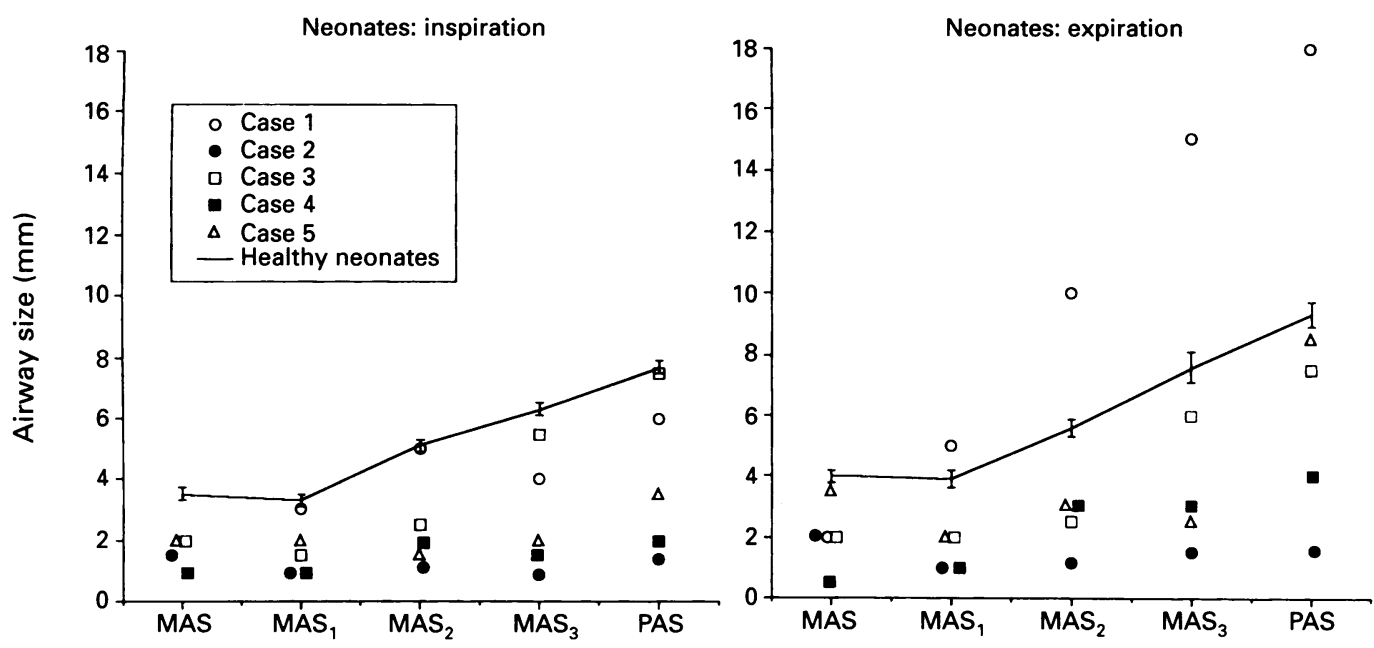

Figure 5 A comparison of upper airway measurements in five study infants in inspiration and expiration compared with 35 healthy neonates of similar age; values are mean (SEM) ${ }^{5}$ The position of airway measurements are detailed in fig 1.
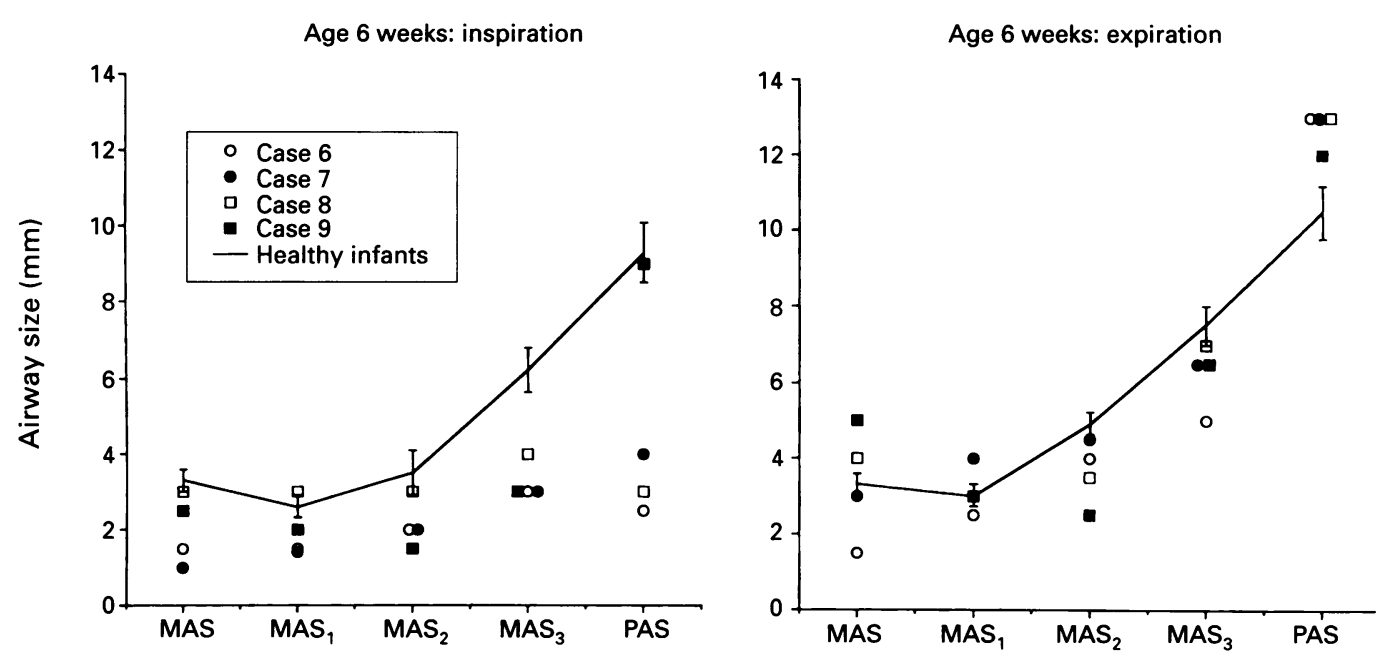

Figure 6 A comparison of upper airway measurements in four study infants in inspiration and expiration compared with 29 healthy infants at 6 weeks of age; values are mean (SEM). ${ }^{5}$

(tables 1,2 , and figs 5,6 ). In five infants, cases $1,6,7,8$, and 9 , the PAS was dilated during expiration compared with the healthy infants. In one further infant, case 5 , the expiratory PAS was dilated relative to a smaller than normal inspiratory airway. The expiratory dilation was particularly marked in case 1 (fig $7 \mathrm{~A}$, B), consistent with a restriction to expiratory flow in the choanal region. This narrowing of the airway on inspiration and ballooning on expiration was no longer apparent when this infant cried (fig 8). Cephalometric measurements of case 2 showed that the angle upper jaw-nasion-lower jaw of $16^{\circ}$ was increased compared with healthy neonates, mean $9.9^{\circ}$, consistent with the clinical sign of a very retracted/small mandible. Paired lateral radiographs demonstrated marked narrowing of the full length of the oropharyngeal airway in both phases of respiration in this baby who eventually required a tracheostomy (table 1 and fig 1). He also had a low position of the larynx typical of the Pierre Robin syndrome.

There were only two infants, cases 6 and 9, who had small upper airways on radiographic evaluation who did not subsequently have apnoea requiring resuscitation, although case 6 was investigated after an episode of apnoea.

\section{Discussion}

We have described a group of nine infants who presented with upper airway problems who were investigated by respiratory phase timed radiographs. In all the nine infants the inspiratory airway measurements were smaller than in healthy infants of a similar age. The level of narrowing of the upper airway was variable. Seven of the nine infants subsequently had apnoeic episodes. All the infants survived.

The pathophysiology of obstructive apnoea during sleep in infants and children is thought to involve an anatomically small airway and/or excess collapsibility of the airway exacerbated by the decrease in muscle tone during sleep. Adults with obstructive sleep apnoea syndrome have a small upper airway as a result of soft tissue thickening or craniofacial abnormalities. ${ }^{67}$

The dimensions of the upper airway alter within the respiratory cycle. It is difficult to time precisely a radiograph to the phase of the respiratory cycle without the use of a device that automatically triggers the $x$ ray machine at the detection of the appropriate respiratory movement. This is especially so in the infant where the respiratory rate is rapid compared with the older child or adult. Also, as airway resistance increases, peak negative inspiratory pressure and thus maximum narrowing of the 
Table 1 Comparison of cephalometric and airway measurements in five study infants compared with 35 healthy neonates of similar age 5 (all measurements in $\mathrm{mm}$ )

\begin{tabular}{|c|c|c|c|c|c|c|c|}
\hline & \multicolumn{2}{|c|}{ Healthy neonates } & \multirow{2}{*}{$\begin{array}{l}\text { Case } 1 \\
(1 \text { week/F) }\end{array}$} & \multirow{2}{*}{$\begin{array}{l}\text { Case } 2 \\
(1 \text { week/M) }\end{array}$} & \multirow{2}{*}{$\begin{array}{l}\text { Case } 3 \\
(2 \text { weeks/F) }\end{array}$} & \multirow{2}{*}{$\begin{array}{l}\text { Case } 4 \\
(3 \text { weeks/M) }\end{array}$} & \multirow{2}{*}{$\begin{array}{l}\text { Case } 5 \\
(3 \text { weeks } / F)\end{array}$} \\
\hline & $M$ & $F$ & & & & & \\
\hline $\begin{array}{l}\text { Nasion-sella } \\
\text { Nasion-upper jaw } \\
\text { Nasion-lower jaw } \\
\text { Angles }\end{array}$ & $\begin{array}{l}52 \cdot 4(0.5) \\
34.9(0.4) \\
49 \cdot 6(0.8)\end{array}$ & $\begin{array}{l}49 \cdot 1(0 \cdot 3) \\
32 \cdot 7(0 \cdot 4) \\
48 \cdot 8(0 \cdot 6)\end{array}$ & $\begin{array}{l}46 \\
33 \\
46\end{array}$ & $\begin{array}{l}50 \\
35 \\
47\end{array}$ & $\begin{array}{l}53 \\
39 \\
\star \star\end{array}$ & $\begin{array}{l}49 \\
35 \\
57\end{array}$ & $\begin{array}{l}50 \\
29 \\
52\end{array}$ \\
\hline $\begin{array}{l}\text { Sella-nasion-upper jaw } \\
\text { Sella-nasion-lower jaw } \\
\text { Upper jaw-nasion-lower jaw } \\
\text { Airway size } \\
\text { MAS }\end{array}$ & $\begin{array}{r}83.5(0.8) \\
73.3(0.7) \\
9.9(0.4)\end{array}$ & $\begin{array}{l}83 \cdot 8(0 \cdot 6) \\
74 \cdot 1(0 \cdot 6) \\
9 \cdot 7(0 \cdot 6)\end{array}$ & $\begin{array}{l}81 \\
70 \\
11\end{array}$ & $\begin{array}{l}78 \\
62 \\
16\end{array}$ & $\begin{array}{l}\star \star \\
\star \star \\
\star \star\end{array}$ & $\begin{array}{l}72 \\
60 \\
12\end{array}$ & $\begin{array}{l}93 \\
76 \\
17\end{array}$ \\
\hline $\begin{array}{l}\text { Inspiration } \\
\text { Expiration } \\
\text { MAS }_{1}\end{array}$ & \multicolumn{2}{|c|}{$\begin{array}{l}3 \cdot 5(0 \cdot 2) \\
4 \cdot 0(0 \cdot 2)\end{array}$} & $\begin{array}{l}2 \cdot 0 \\
2 \cdot 0\end{array}$ & $\begin{array}{l}1.5 \\
2 \cdot 0\end{array}$ & $\begin{array}{l}2 \cdot 0 \\
2 \cdot 0\end{array}$ & $\begin{array}{l}1.0 \\
0.5\end{array}$ & $\begin{array}{l}2 \cdot 0 \\
3 \cdot 5\end{array}$ \\
\hline $\begin{array}{l}\text { Inspiration } \\
\text { Expiration }\end{array}$ & \multicolumn{2}{|c|}{$\begin{array}{l}3.3(0.2) \\
3.9(0.3)\end{array}$} & $\begin{array}{l}3 \cdot 0 \\
5 \cdot 0\end{array}$ & $\begin{array}{l}1 \cdot 0 \\
1 \cdot 0\end{array}$ & $\begin{array}{l}1.5 \\
2.0\end{array}$ & $\begin{array}{l}1 \cdot 0 \\
1 \cdot 0\end{array}$ & $\begin{array}{l}2 \cdot 0 \\
2 \cdot 0\end{array}$ \\
\hline $\begin{array}{l}\text { Inspiration } \\
\text { Expiration } \\
\mathrm{MAS}_{3}\end{array}$ & \multicolumn{2}{|c|}{$\begin{array}{l}5 \cdot 1(0 \cdot 3) \\
5 \cdot 6(0.3)\end{array}$} & $\begin{array}{r}5 \cdot 0 \\
10 \cdot 0\end{array}$ & $\begin{array}{l}1 \cdot 0 \\
1 \cdot 0\end{array}$ & $\begin{array}{l}2.5 \\
2.5\end{array}$ & $\begin{array}{l}2 \cdot 0 \\
3 \cdot 0\end{array}$ & $\begin{array}{l}1.5 \\
3 \cdot 0\end{array}$ \\
\hline $\begin{array}{l}\text { Inspiration } \\
\text { Expiration } \\
\text { PAS }\end{array}$ & \multicolumn{2}{|c|}{$\begin{array}{l}6.3(0.3) \\
7.6(0.5)\end{array}$} & $\begin{array}{r}4 \cdot 0 \\
15 \cdot 0\end{array}$ & $\begin{array}{l}1 \cdot 0 \\
1 \cdot 5\end{array}$ & $\begin{array}{l}5 \cdot 5 \\
6 \cdot 0\end{array}$ & $\begin{array}{l}1 \cdot 5 \\
3 \cdot 0\end{array}$ & $\begin{array}{l}2 \cdot 0 \\
2 \cdot 5\end{array}$ \\
\hline $\begin{array}{l}\text { Inspiration } \\
\text { Expiration }\end{array}$ & \multicolumn{2}{|c|}{$\begin{array}{l}7.7(0.3) \\
9.3(0.4)\end{array}$} & $\begin{array}{r}6 \cdot 0 \\
18 \cdot 0\end{array}$ & $\begin{array}{l}1.5 \\
1.0\end{array}$ & $\begin{array}{l}7 \cdot 5 \\
7 \cdot 5\end{array}$ & $\begin{array}{l}2 \cdot 0 \\
4 \cdot 0\end{array}$ & $\begin{array}{l}3 \cdot 5 \\
8 \cdot 5\end{array}$ \\
\hline
\end{tabular}

${ }^{\star}$ Measurements given as mean (SEM). ${ }^{\star \star}$ Tip of lower incisor tooth in mandible unidentifiable.

Airway measurements made: MAS on line between gnathion to anterior sella wall; MAS 1 on line between gnathion to posterior sella wall; PAS on line gnathion to gonion extended; $\mathrm{MAS}_{3}$ on gnathion to point on anterior air shadow $0.5 \mathrm{~cm}$ perpendicular to line gnathion to gonion; $M A S_{2}$ on line gnathion to bisect angle made by lines $M_{A} S_{1}$ and $M A S_{3}$.

Table 2 Comparison of cephalometric and airway measurements in four study infants compared with 29 healthy 6 week infants ${ }^{5}$ (all measurements in $\mathrm{mm}$ )

\begin{tabular}{|c|c|c|c|c|c|c|}
\hline & \multicolumn{2}{|c|}{$\begin{array}{l}\text { Healthy infants* } \\
\text { ( } 6 \text { weeks) }\end{array}$} & \multirow{2}{*}{$\begin{array}{l}\text { Case } 6 \\
(5 \text { weeks/M) }\end{array}$} & \multirow{2}{*}{$\begin{array}{l}\text { Case } 7 \\
(6 \text { weeks/F) }\end{array}$} & \multirow{2}{*}{$\begin{array}{l}\text { Case } 8 \\
(6 \text { weeks/F) }\end{array}$} & \multirow{2}{*}{$\begin{array}{l}\text { Case } 9 \\
\text { (5 months/M) }\end{array}$} \\
\hline & $M$ & $F$ & & & & \\
\hline Nasion-sella & $55 \cdot 6(0 \cdot 6)$ & $53.7(0 \cdot 6)$ & 52 & $\star \star$ & 53 & 59 \\
\hline Nasion-upper jaw & $37.6(0 \cdot 7)$ & $36 \cdot 7(0 \cdot 8)$ & 35 & $\star \star$ & 33 & 33 \\
\hline $\begin{array}{l}\text { Nasion-lower jaw } \\
\text { Angles }\end{array}$ & $55 \cdot 4(1 \cdot 0)$ & $55 \cdot 2(0 \cdot 7)$ & 50 & $\star \star$ & 51 & 51 \\
\hline Sella-nasion-upper jaw & $85 \cdot 6(1 \cdot 1)$ & $84 \cdot 4(0 \cdot 8)$ & 83 & $\star \star$ & 94 & 90 \\
\hline Sella-nasion-lower jaw & $76 \cdot 1(1 \cdot 0)$ & $75.9(0.7)$ & 75 & $\star \star$ & 82 & 84 \\
\hline Upper jaw-nasion-lower jaw & $9 \cdot 7(0.6)$ & $8.6(0.6)$ & 8 & $\star \star$ & 12 & 6 \\
\hline \multirow{2}{*}{\multicolumn{7}{|c|}{$\begin{array}{l}\text { Airway size } \\
\text { MAS }\end{array}$}} \\
\hline & & & & & & \\
\hline Inspiration & \multirow{2}{*}{\multicolumn{2}{|c|}{$\begin{array}{l}3.3(0.3) \\
3.3(0.3)\end{array}$}} & $1 \cdot 5$ & $1 \cdot 0$ & $3 \cdot 0$ & $2 \cdot 5$ \\
\hline Expiration & & & 1.5 & $3 \cdot 0$ & $4 \cdot 0$ & $5 \cdot 0$ \\
\hline \multicolumn{7}{|l|}{ MAS $_{1}$} \\
\hline Inspiration & \multicolumn{2}{|c|}{$2 \cdot 6(0 \cdot 3)$} & $1 \cdot 5$ & $1 \cdot 4$ & $3 \cdot 0$ & $2 \cdot 0$ \\
\hline Expiration & \multirow{2}{*}{\multicolumn{2}{|c|}{$3 \cdot 0(0 \cdot 3)$}} & $2 \cdot 5$ & $4 \cdot 0$ & $3 \cdot 0$ & $3 \cdot 0$ \\
\hline $\mathrm{MAS}_{2}$ & & & & & & \\
\hline Inspiration & \multirow{2}{*}{\multicolumn{2}{|c|}{$\begin{array}{l}3.5(0.6) \\
4.9(0.3)\end{array}$}} & $2 \cdot 0$ & $2 \cdot 0$ & $3 \cdot 0$ & 1.5 \\
\hline Expiration & & & $4 \cdot 0$ & $4 \cdot 5$ & $3 \cdot 5$ & $2 \cdot 5$ \\
\hline $\mathrm{MAS}_{3}$ & \multirow{3}{*}{\multicolumn{2}{|c|}{$6 \cdot 2(0 \cdot 6)$}} & & & & \\
\hline Inspiration & & & $3 \cdot 0$ & $3 \cdot 0$ & $4 \cdot 0$ & $3 \cdot 0$ \\
\hline Expiration & & & $5 \cdot 0$ & 6.5 & $7 \cdot 0$ & 6.5 \\
\hline PAS & \multicolumn{2}{|c|}{$7 \cdot 5(0.5)$} & & & & \\
\hline Inspiration & \multirow{2}{*}{\multicolumn{2}{|c|}{$\begin{array}{r}9 \cdot 3(0 \cdot 8) \\
10 \cdot 5(0 \cdot 7)\end{array}$}} & $2 \cdot 5$ & $4 \cdot 0$ & $3 \cdot 0$ & $9 \cdot 0$ \\
\hline Expiration & & & $13 \cdot 0$ & $13 \cdot 0$ & $13 \cdot 0$ & $12 \cdot 0$ \\
\hline
\end{tabular}

airway occurs proportionately earlier in the inspiratory phase ${ }^{8}$ making timing of the exposure by visual observation even more unreliable. The method that we have described $^{5}$ and have used here is inexpensive and easy to use.

We have previously reported that the dimensions of the oropharyngeal airway during inspiration are smaller in 6 week old infants than in neonates. ${ }^{5}$ This decrease in airway size could result from increased mucosal thickness. Alternatively, the increase in inspiratory narrowing at 6 weeks may result from increased upper airway compliance related to neurogenic or other mechanisms. A role of neurogenic mechanisms in upper airway dysfunction during sleep is supported by a report that in some newborn infants who are prone to obstructive apnoea, occlusion of the nasal airway during sleep leads to upper airway closure associated with a failure to increase activity in the genioglossis and upper airway muscles with inspiration. ${ }^{9}$ Resistance to airflow through a tube varies with the radius raised to the 4th power (Poiseuille's law). Thus, with airway narrowing resistance increases disproportionately; the level of negative pressure generated to maintain tidal volume places the airway at risk for complete closure. ${ }^{10}$ Although the subjects of the current report had diverse aetiologies for airway dysfunction, for example, choanal narrowing in case 1 and abnormal position of the tongue in Pierre Robin syndrome in case 2 , serious consequences of the airway abnormalities developed after an asymptomatic period after birth.

In 1952 Whitehouse and Holt reported that in choanal occlusion there is pharyngeal collapse during inspiration and pharyngeal ballooning during expiration. ${ }^{11}$ However, some other early investigators reported airway ballooning during inspiration ${ }^{12}$ and this latter 

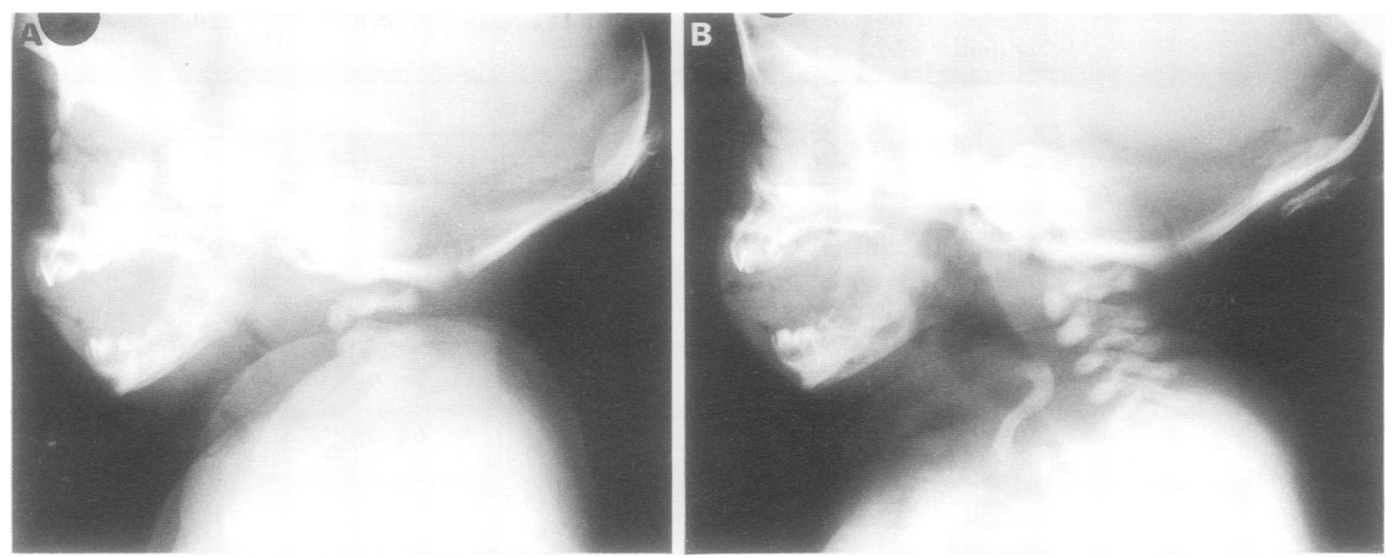

Figure 7 Radiographs of the upper airway during quiet nasal breathing in case 1: $(A)$ inspiration and (B) expiration. Note the narrow nasopharyngeal space on inspiration and the ballooning in this region on expiration.

error has been perpetuated in many medical texts. As we have demonstrated, lateral upper airway radiographs that are precisely timed in the respiratory cycle are necessary to place the fluctuations in pharyngeal size accurately within that cycle. Five infants demonstrated ballooning of the pharyngeal space behind the soft palate during expiration consistent with a fixed restriction to expiratory airflow. In four infants (cases 2, 3, 4, and 5) the pharyngeal airway increased slightly during expiration but remained narrowed compared with the airway of healthy infants. This finding suggests that the oropharyngeal airway was inherently small in addition to showing excess collapsibility during inspiration. As described in infants with glossoptosis syndrome $\mathrm{e}^{13}$ in case 4 , the tongue was drawn back and up in the mouth with inspiration, forming a seal with the mid-hard palate. Hence, the area of increased airway resistance is likely to have been above the level of the oropharynx in this infant.

A small posterior airway, measured in lateral upper airway radiographs along the line, gnathion-gonion, was reported by Guilleminault et al to be a familial risk factor in a group of infants who presented with ALTEs. ${ }^{14}$ The respiratory phase of their films are not stated. They reported that the posterior airway space measured $11 \mathrm{~mm}$ in the adult. We have reported that the posterior airway space during expiration in healthy 6 week old infants is $10.5 \mathrm{~mm}, 5$ almost adult size. ${ }^{14}$ The expira-

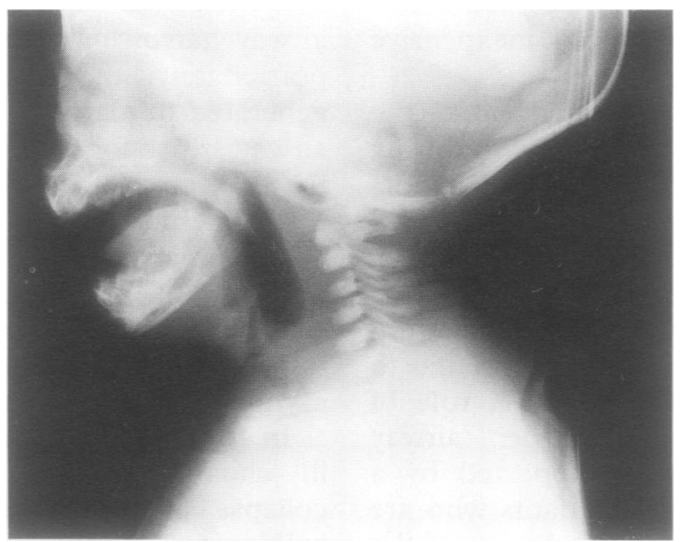

Figure 8 Radiograph of the upper airway on inspiration during crying in case 1 . Note that the pharyngeal airway is widely dilated. tory phase airway measurements at the PAS (fig 1) in two infants (cases 2 and 4), are markedly diminished compared with healthy infants and with adults. However, four of our patients (cases 1, 6, 7, and 8) demonstrated narrowing of the posterior airway space restricted to the inspiratory phase and showed marked ballooning on expiration.

Cephalometric measurements in the infant with Pierre Robin syndrome showed the angle, upper jaw-nasion-lower jaw (A-N-B, fig 1) to be markedly increased compared with healthy infants. This finding, also shown in case 5 , is consistent with the clinical sign of posteriorly displaced mandible. Couly and LeLivre reported a mortality rate in infants with Pierre Robin syndrome of up to $25 \% .^{15}$ Most deaths with this syndrome are unexplained and occur during sleep. ${ }^{15}$ We suggest obstructive sleep apnoea has a role in these deaths.

\section{Conclusions}

Our experience suggests that it is possible to identify clinically some infants in early infancy who are at risk for subsequent life threatening apnoeic events. Attention should be given to infants with micrognathia when there are signs of inspiratory intercostal and lateral pharyngeal indrawing suggestive of upper airway compromise. Infants with a family history of ALTEs or SIDS should also receive such consideration. Respiratory phase timed lateral upper airway radiographs can assist in the evaluation of upper airway abnormalities.

We thank the radiographers at St Helen's Hospital and at National Women's Hospital, Auckland, New Zealand for producing the radiographs shown in this study, and J Urry of National Women's Hospital for his photographic reproductions. Modifications to the apnoea alarm to produce the timed radiographs were designed by Dr Martin Wright (Director of Medical Electronics, Northwick Park Hospital, Harrow, Middlesex), and their production funded by the Turanga Trust, Gisborne. Dr Davis is funded by the Cot Death Association, a division of the National Child Health Research Foundation of New Zealand, Drs Tonkin and Gunn by the Turanga Trust. Radiographs and videotapes are available from the authors on request.

1 Kahn A, Blum D, Rebuffat E, et al. Polygraphic studies of infants who subsequently died of sudden infant death syndrome. Pediatrics 1988; 82: 721-7.

2 Guilleminault C, Ariagno RL, Forno LS, Nagel L, Baldwin $R$, Owen $M$. Obstructive sleep apnea and near miss for SIDS: 1 . Report of an infant with sudden death. Pediatrics 1979; 63: 837-43.

3 Guilleminault C, Hill MW, Blair Simmons F, Dement WC Obstructive sleep apnea: electromyographic and fibreoptic studies. Exp Neurol 1978; 62: 48-67. 
4 Southall DP, Croft CB, Stebbens VA, Ibrahim H, Buchdahl $\mathrm{R}$, Warner JO. Detection of sleep associated dysfunctional pharyngeal obstruction in infants. Eur $\mathcal{F}$ Pediatr 1989; 148: 353-9.

5 Gunn TR, Tonkin SL. Upper airway measurements during inspiration and expiration in infants. Pediatrics 1989; 84: inspir.

6 Jamieson A, Guilleminault C, Partinen M, Quera-Salva MA. Obstructive sleep apnoea patients have craniomandibular abnormalities. Sleep 1986; 9: 469-77.

7 Partinen M, Guilleminault C, Quera-Salva MA, Jamieson A. Obstructive sleep apnea and cephalometric roentgenograms: the role of craniofacial abnormalities in the definition of abnormal breathing during sleep. Ches 1988; 93: 1199-205.

8 Tonkin SL, Partridge J, Beach B, Withy S. The pharyngeal effect of partial nasal obstruction. Pediatrics 1979; 63: 261-71.

9 Cohen G, Henderson-Smart DJ. Upper airway muscle activity during nasal occlusion in newborn babies. $\mathcal{f} A p p l$ Physiol 1989; 66: 1328-35.

10 Tonkin S, Beach D. The vulnerability of the infant upper airway. In: Harper RM, Hoffman HJ, eds. Sudden infant death syndrome. Risk factors and basic mechanisms. New death syndrome. Risk factors and basic mechanisms.

11 Whitehouse WM, Holt JF. Paradoxical expiratory ballooning of the hypopharynx in siblings with bilateral choanal atresia. Radiology 1952; 59: 216-20.

12 Hay PD. Annals of roentgenology. Vol IX. The neck. New York: Paul Hoeber, 1930: 87-8.

13 Cozzi F, Pierro A. Glossoptosis-apnea syndrome in infancy. Pediatrics 1985; 75: 836-43.

14 Guilleminault C, Helott G, Powell N, Riley R. Small upper airways in near-miss sudden infant death infants and their families. Lancet 1986; i: 402-7.

15 Couly G, LeLivre-Ayre C. La crete neurale cephalique et les malformation cephalofaciales humaines. Revue Pediatrie malformation cephalofacia
(Paris) 1983; 19: 5-21. 